\title{
Studies on the Hydrodesulfurization Catalysts of Residual Fuels (Part 7)
}

\author{
-Regeneration of Used Catalysts*- \\ by Masao Inoguchi*1, Satoshi Sakurada*2, Yoshihito Satomi*3, Kiyohiko Inaba*4, \\ Harumi Kagaya*5, Kazuhito Tate*6, Takehiko Mizutori*7, Reijiro Nishiyama*8, \\ Tamotsu Nagai*g and Saburo Onishi*10
}

\begin{abstract}
Summary: The catalysts used for the long run activity tests of hydrodesulfurization reaction of the residual fuel were regenerated by burning with air. Physical properties and the desulfurization activity of the regenerated catalysts were studied. From the experimental results, the following conclusions were obtained.

1) The specific surface area of the catalysts used for the long run activity tests decreased to $40 \%$ of the original value of the fresh catalysts. The specific surface area after regeneration recovered up to $50 \%$ in the upper part of the catalyst bed and about $70 \%$ in the lower part. The specific surface area of the catalysts after about 100 hours on siream was almost completely regenerated. The pore volume also varied in proportion to the degree of recovery of the specific surface area. The mean pore diameter became greater than that of the fresh catalyst by regeneration.

2) The pore size distribution varied remarkably during the 100 hours on stream from the start, and after which it maintained almost the same distribution. Pores were plugged up by the deposited carbon and metals on the surface of the catalyst. Sites of the plugged up pores were considered to be different with different catalysts. The pore size distribution recovered more at the upper part of the catalyst bed than at the lower part after regeneration.

3) When the decrease in the catalyst activity was caused by the deposited carbon, the major part of the activity was recovered after regeneration. However, when the decrease in the activity was due to the deposited metals like vanadium etc., the activity was not recovered, since the metals could not be removed by regeneration.
\end{abstract}

\section{Introduction}

The decrease in the activity of the catalysts used for desulfurization of distillates is caused

\footnotetext{
* Received July 3, 1972.

The study was carried out by Research and Development Association of Residual Fuel Hydrodesulfurization.

*1 Central Research Laboratory, Showa Oil Co., Ltd. (123-1, Ninoiki, Aza, Shimokawairi, Atsugi-shi, Kanagawa-Pref., Japan)

*2 Central Research Laboratory, Toa Nenryo Kogyo K. K.

* Central Research Laboratory, Nippon Mining Co., Ltd.

*4 Production \& Refinery Co-ordination Dept., Daikyo Oil Co., Ltd.

*s Research Section of Kawasaki Refinery, Toa Oil Co., Ltd.

*6 Research Laboratory, Mitsubishi Oil Co., Ltd.

*7 Research Section of Kawasaki Refinery, Asia Oil Co., Ltd.

*B Research Laboratory of Osaka Refinery, Koa Oil Co., Ltd.

* Research Section of Kawasaki Refinery, General Oil Refining Co., Ltd.

*10 Central Research Laboratory, Maruzen Oil Co., Ltd.
}

mainly by the deposited carbon on the surfaces of the catalysts. Therefore, the activity could be regenerated by removing the carbon. On the other hand, in case of desulfurization of residual fuels, decomposition of organic metallic compounds contained therein took place in parallel with the desulfurization reaction, and both carbon and the metals deposited on the catalysts. Therefore, the degree of recovery in the activity after regeneration between the catalysts used for distillates and that for residual fuels was considered to be different. However, up to the present, papers dealing with the state of the activity of the regenerated catalysts used for desulfurization of residual fuels in connection with the change in their physical properties were not available.

In the desulfurization of residual fuel which contained considerable amounts of poisoning materials such as asphaletene and organic metallic compounds, the catalyst activity was greatly

Volume 14, No. 2, November 1972 
affected by the physical properties of the catalyst, especially, its mean pore diameter and pore size distribution. For instance, it became obvious from the relation between the physical properties and desulfurization activity ${ }^{1}$, long run activity tests $^{2)}$ and observation by X-ray microanalyzer ${ }^{3}$ ) of the deposited materials on the surface of the catalyst after long run tests that the catalyst which had fewer pores of less than $100 \AA$ in diameter seemed to show a longer catalyst life.

Here, the authors regenerated by burning with air the catalysts which were used in hydrodesulfurization of residual fuels for a long period of time and they studied which of such physical properties as specific surface area, pore volume, mean pore diameter and pore size distribution curve would be more markedly affected by regeneration. Also they studied how the changes in the physical properties by regeneration affected the desulfurization activity. The authors will report the results of the above investigation.

\section{Experimental}

\subsection{Regeneration of Catalysts}

A quartz tube $20 \mathrm{~mm}$ in inner diameter externally heated by an electric furnace was used for regeneration of the used catalysts. Three thermocouples were inserted into the center of the tube to control the temperature of the catalyst bed. About $20 \mathrm{~g}$ of a catalyst sample was placed in the center of the tube which was fixed with quartz wool wads. $\mathrm{N}_{2}$ gas containing $2 \%$ of $\mathrm{O}_{2}$ was streamed at $500 \mathrm{ml} / \mathrm{min}$ and the sample was burned for 8 hours at $400^{\circ} \mathrm{C}$ and further burned for 8 hours at $500^{\circ} \mathrm{C}$. The carbon dioxide generated was checked gas chromatographically.

Such physical properties of regenerated catalysts as specific surface areas, pore volumes, mean pore diameters and pore size distributions were measured by mean of BET and CI methods.

\subsection{Samples Used for the Experiments}

The catalysts used in the present experiments were those that were used in long run activity tests $^{2)}$. They were KC-28, KS-83, KS-97 (more than 3,000 hours on stream) and KS-103, KS-111, KS-124 (more than 2,100 hours on stream). As for the former group, each catalyst bed was divided into four parts in which the upper and the lower parts were used and that of the latter was divided into five parts in which the second part from the top was used.
The catalyst, which was on stream for 100 hours, was used in the activity test of Khafji residual fuel under the following conditions: reaction temperature $410^{\circ} \mathrm{C}$, LHSV $1.0 \mathrm{hr}^{-1}$, reaction pressure $100 \mathrm{~kg} / \mathrm{cm}^{2}$ and $\mathrm{H}_{2}$ gas rate $1,000 l$ $\mathrm{H}_{2} / l-o i l$. As for regeneration pretreatment, effects of the oil remaining on the sample surface were examined on the following two kinds of samples: one was treated with benzene to remove the oil by Soxhlet extractor and the other was used without any treatment. Their physical properties were compared after regeneration, and there were no differences found in the two samples. Therefore, the oil removal treatment was omitted except when the physical properties of the catalyst on whose surface carbon deposited were measured.

\subsection{Activity Tests on Regenerated Catalysts}

The same experimental apparatus as that used in a previous paper ${ }^{1)}$ was used. The reaction conditions were the same as those used in the usual activity tests: i.e., the reaction temperature of $410^{\circ} \mathrm{C}$, reaction pressure of $100 \mathrm{~kg} / \mathrm{cm}^{2}$, LHSV of $1.0 \mathrm{hr}^{-1}, \mathrm{H}_{2}$ gas rate of $1,000 l-\mathrm{H}_{2} / l$-oil, time on stream of 100 hours and as the feed oil Kuwait residual fuel of the general properties shown in Table 1 was used. The amount of sulfur removal was calculated as reported in the previous paper ${ }^{1)}$.

\section{Results and Discussion}

\subsection{Effects on the Physical Properties of Catalysts}

In Table 2 and 3, such physical properties of each catalyst as specific surface area, pore volume, mean pore diameter etc., are shown. Referring to Table 2, some consideration on the results of the specific surface area obtained by the BET method was made. The specific surface area of

Table 1 The Properties of Kuwait Atmospheric Residue

\begin{tabular}{lr|c}
\hline & & Kuwait \\
\hline Specific Gravity & $\left(15 / 4^{\circ} \mathrm{C}\right)$ & 0.953 \\
Kinematic Viscocity at $50^{\circ} \mathrm{C}$ & $(\mathrm{cSt})$ & 191 \\
Flash Point & $\left({ }^{\circ} \mathrm{C}\right)$ & 140 \\
Pour Point & $\left({ }^{\circ} \mathrm{C}\right)$ & -5 \\
Carbon Residue & $($ wt $\%)$ & 9.10 \\
Ash Content & $($ wt $\%)$ & 0.03 \\
Water Content & $($ vol $\%)$ & 0.02 \\
Asphaltene Content & $($ wt $\%)$ & 2.4 \\
Elements, Carbon & $($ wt $\%)$ & 83.89 \\
Hydrogen & $($ wt $\%)$ & 11.47 \\
Sulfur & $($ wt $\%)$ & 3.62 \\
Nitrogen & $($ wt $\%)$ & 0.187 \\
Metals, Vanadium & (wt. ppm) & 51 \\
Nickel & (wt. ppm) & 13 \\
\hline
\end{tabular}

Bulletin of The Japan Petroleum Institute 
Table 2 Physical Properties of Catalysts Used in the Long Run Activity Tests

\begin{tabular}{|c|c|c|c|c|c|c|c|c|}
\hline \multirow[b]{2}{*}{$\begin{array}{l}\text { Catalyst } \\
\text { No. }\end{array}$} & \multirow[b]{2}{*}{$\begin{array}{l}\text { Time on } \\
\text { Stream } \\
\text { (hr) }\end{array}$} & & \multicolumn{3}{|c|}{ BET Method } & \multicolumn{3}{|c|}{ GI Method } \\
\hline & & & $\begin{array}{c}\text { Specific } \\
\text { Surface } \\
\text { Area } \\
\left(\mathrm{m}^{2} / \mathrm{g}\right)\end{array}$ & $\begin{array}{c}\text { Pore } \\
\text { Volume } \\
(\mathrm{m} l / \mathrm{g})\end{array}$ & $\begin{array}{c}\text { Mean Pore } \\
\text { Diameter } \\
(\AA)\end{array}$ & $\begin{array}{c}\text { Specific } \\
\text { Surface } \\
\text { Area } \\
\left(\mathrm{m}^{2} / \mathrm{g}\right)\end{array}$ & $\begin{array}{l}\text { Pore } \\
\text { Volume } \\
(\mathrm{ml} / \mathrm{g})\end{array}$ & $\begin{array}{l}\text { Mean Pore } \\
\text { Diameter } \\
(\AA)\end{array}$ \\
\hline \multirow{4}{*}{$\mathrm{KC}-28$} & \multirow{3}{*}{3,004} & Fresh & 239.4 & 0.458 & 76.5 & 290.4 & 0.477 & 73.3 \\
\hline & & $\begin{array}{ll}\text { Spent } & \mathrm{U} \\
& \mathrm{L}\end{array}$ & $\begin{array}{l}105.7 \\
101.6\end{array}$ & $\begin{array}{l}0.172 \\
0.187\end{array}$ & $\begin{array}{l}65.1 \\
73.6\end{array}$ & $\begin{array}{l}109.7 \\
144.5\end{array}$ & $\begin{array}{l}0.173 \\
0.204\end{array}$ & $\begin{array}{l}71.5 \\
64.6\end{array}$ \\
\hline & & $\begin{array}{ll}\text { Regen } & \mathrm{U} \\
\mathrm{L}\end{array}$ & $\begin{array}{l}119.2 \\
169.5\end{array}$ & $\begin{array}{l}0.233 \\
0.343\end{array}$ & $\begin{array}{l}78.2 \\
80.9\end{array}$ & $\begin{array}{l}148.2 \\
208.9\end{array}$ & $\begin{array}{l}0.250 \\
0.359\end{array}$ & $\begin{array}{l}73.7 \\
78.0\end{array}$ \\
\hline & 100 & $\begin{array}{l}\text { Spent Mix } \\
\text { Regen Mix }\end{array}$ & 249.7 & 0.460 & 73.7 & 283.8 & 0.475 & 75.4 \\
\hline \multirow{4}{*}{ KS-83 } & \multirow{3}{*}{3,010} & Fresh & 128.1 & 0.367 & 114.6 & 135.0 & 0.327 & 124.0 \\
\hline & & $\begin{array}{ll}\text { Spent } & \text { U } \\
& \text { L }\end{array}$ & $\begin{array}{l}54.6 \\
49.6\end{array}$ & $\begin{array}{l}0.144 \\
0.140\end{array}$ & $\begin{array}{l}105.4 \\
112.9\end{array}$ & $\begin{array}{l}63.7 \\
47.4\end{array}$ & $\begin{array}{l}0.136 \\
0.127\end{array}$ & $\begin{array}{l}111.2 \\
132.2\end{array}$ \\
\hline & & $\begin{array}{ll}\text { Regen } & \mathbf{U} \\
& \mathrm{L}\end{array}$ & $\begin{array}{l}68.6 \\
81.3\end{array}$ & $\begin{array}{l}0.197 \\
0.259\end{array}$ & $\begin{array}{l}114.9 \\
127.4\end{array}$ & $\begin{array}{l}61.6 \\
81.3\end{array}$ & $\begin{array}{l}0.178 \\
0.224\end{array}$ & $\begin{array}{l}143.6 \\
141.1\end{array}$ \\
\hline & 100 & $\begin{array}{l}\text { Spent Mix } \\
\text { Regen Mix }\end{array}$ & 198.1 & 0.683 & 137.8 & 235.0 & 0.601 & 141.6 \\
\hline \multirow{4}{*}{ KS-97 } & \multirow{3}{*}{3,017} & Fresh & 106.0 & 0.401 & 151.3 & 116.0 & 0.245 & 117.0 \\
\hline & & $\begin{array}{ll}\text { Spent } & \mathrm{U} \\
\mathrm{L}\end{array}$ & $\begin{array}{l}56.0 \\
54.0\end{array}$ & $\begin{array}{l}0.130 \\
0.134\end{array}$ & $\begin{array}{l}92.9 \\
99.3\end{array}$ & $\begin{array}{l}43.6 \\
39.4\end{array}$ & $\begin{array}{l}0.122 \\
0.113\end{array}$ & $\begin{array}{l}139.9 \\
147.1\end{array}$ \\
\hline & & $\begin{array}{ll}\text { Regen } & \mathbf{U} \\
& \mathrm{L}\end{array}$ & $\begin{array}{l}49.2 \\
82.9\end{array}$ & $\begin{array}{l}0.182 \\
0.302\end{array}$ & $\begin{array}{l}148.1 \\
145.8\end{array}$ & $\begin{array}{l}42.3 \\
79.9\end{array}$ & $\begin{array}{l}0.131 \\
0.229\end{array}$ & $\begin{array}{l}155.5 \\
148.8\end{array}$ \\
\hline & 100 & $\begin{array}{l}\text { Spent Mix } \\
\text { Regen Mix }\end{array}$ & 109.5 & 0.267 & 97.5 & 110.4 & 0.307 & 145.1 \\
\hline Notes & $\begin{array}{l}\text { ent: Used } \\
\text { en: Reg } \\
\text { U: Upp } \\
\text { L: Low } \\
\text { esh: New }\end{array}$ & $\begin{array}{l}\text { art of } \\
\text { alyst. }\end{array}$ & $\begin{array}{l}\text { bed. } \\
\text { bed. }\end{array}$ & & & & & \\
\hline
\end{tabular}

KC-28 sample, which was about 100 hours on stream, recovered almost completely its original value after regeneration. The value of the sample, which was subjected only to the oil removal treatment, decreased after 3,000 hours on stream, to about $40 \%$ of its original value in both the upper and the lower part of the catalyst bed. After regeneration, the value had recovered to about $50 \%$ in the upper part and to $70 \%$ in the lower part. The difference in the recovery ratio was considered to be due to the difference in the amounts of metals deposited between the upper and the lower part. As was shown in previous paper ${ }^{3)}$, there was more deposition of a metal like vanadium in the upper part of the catalyst bed than in the lower part, thus the specific surface area would have decreased more in the upper part.

Next, the changes in the pore volumes were observed. The pore volume decreased to $40 \%$ of its original volume in both the upper and the lower part of the catalyst bed, and after regeneration, it recovered to about $50 \%$ for the upper part and about $75 \%$ for the lower part. The mean pore dimameter after regeneration tended to become greater than that of the fresh catalyst. It was considered that comparatively small pores were plugged up by deposition on the catalyst during its long period of run, and thus the mean pore diameter became greater.

Now, the results of KS-83 and KS-97 in Table 2 are compared with those of $\mathrm{KC}-28$. Similar to the tendency shown by $\mathrm{KS}-28$, the various physical properties of KS-83 and KS-97 decreased from their original values, and the extent of their recoveries after regeneration was about as same as that of $\mathrm{KC}-28$. As the results obtained by BET and CI methods showed the same tendency, only the results obtained by BET method were used for comparison. 
Table 3 Physical Properties of Catalysts Used in the Long Run Activity Tests

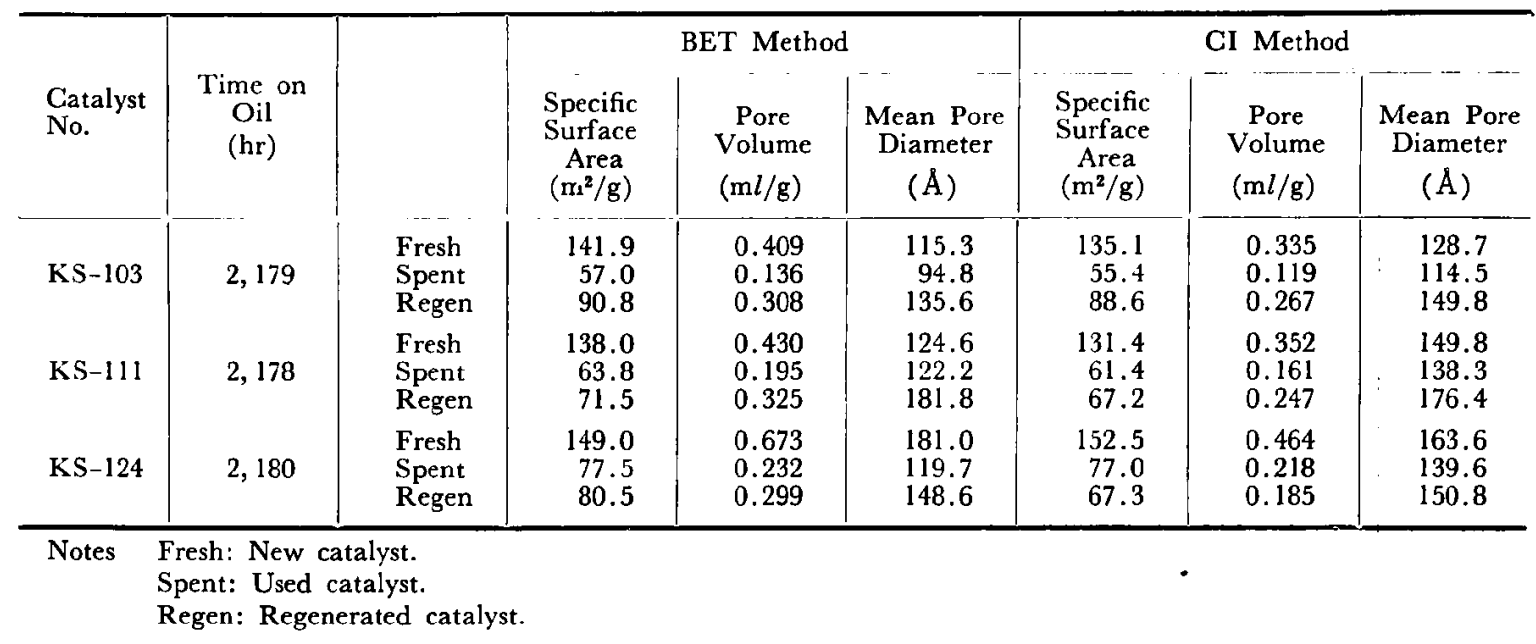

In the following, the results obtained with the catalysts used in the long run activity tests of 2,180 hours are shown in Table 3. The specific surface area of the trial catalyst $\mathrm{KS}-124$, which showed the longest life, decreased from the original $149 \mathrm{~m}^{2} / \mathrm{g}$ to $77.5 \mathrm{~m}^{2} / \mathrm{g}$ after the long run activity test, corresponding to $48 \%$ decrease. As for the catalyst subjected to the oil removal treatment, the specific surface area after regeneration was $80.5 \mathrm{~m}^{2} / \mathrm{g}$, a small increase. Therefore, the effect of carbon deposit on the second part of five parts from the top of the catalyst bed was estimated to be slight. As a significant factor to lessen the specific surface area, the possible influence of the metals deposited on the catalyst was considered, because they might plug up the pores.

The pore volume of fresh catalyst was 0.673 $\mathrm{m} l / \mathrm{g}$ and that of the used catalyst was $0.232 \mathrm{ml} / \mathrm{g}$ with carbon deposit, and the ratio of decrease amounted to $65 \%$. This decrease was considered to be due to the plugging up of small pores with metals and carbon. By regeneration, the pore volume increased to $0.299 \mathrm{ml} / \mathrm{g}, 10 \%$ in the recovery ratio. The mean pore diameter of the used catalyst decreased from $181.0 \AA$ of the fresh to $119.7 \AA$ with carbon deposit. The ratio of decrease was $34 \%$. After regeneration, it was 148.6 $\AA$. This was an apparent recovery caused by plugging up of small pores. The results showed the same tendency as those of $\mathrm{KC}-28$, etc., described elsewhere. The results obtained on KS-124 showed the same tendency as those of KS-103 and KS-111 as regards specific surface area, pore volume and mean pore diameter for fresh used and regenerated catalysts, respectively. From a series of experimental results, it became clear, as for $\mathrm{KS}-103$, that the decrease in the ratio of specific surface area and pore volume of the used catalyst with carbon deposit was almost the same as that of the other catalysts, but the recovery after regeneration became greater than the others. In the long run activity tests, the range of the reaction temperatures used was from 380 to $430^{\circ} \mathrm{C}$. On the other hand, that of $\mathrm{KS}-103$ was limited to $410^{\circ} \mathrm{C}, 20^{\circ} \mathrm{C}$ lower than the other catalysts; so the metals and carbon were considered to deposit on the catalyst in different conditions.

\subsection{Effects on Pore Size Distribution}

The variation of pore size distribution of catalyst KS-43 with time used in the long run tests was examined. The pore size distribution of the fresh catalyst and that of the catalyst after 100 hours on stream and 1,000 hours on stream which were subjected to the oil removal treatment are shown in Fig. 1. Comparing the catalyst used for 100 hours on stream with the fresh, pores below $200 \AA$ in diameter decreased, and pores below $30 \AA$ in diameter disappeared. The pore size distribution of the catalyst after 1,134 hours on stream showed almost the same tendency as that of the catalyst after 100 hours on stream except that pores below $50 \AA$ in diameter disappeared. On the basis of this information, such consideration can be made. As shown in a previous paper, the amount of carbon deposited on the catalyst became constant after about 100 hours on stream. Therefore, it was considered that the remarkable difference in the pore size distribution curves between the start of the test and 100 hours on stream was due to the influence of the carbonaceous materials depo- 


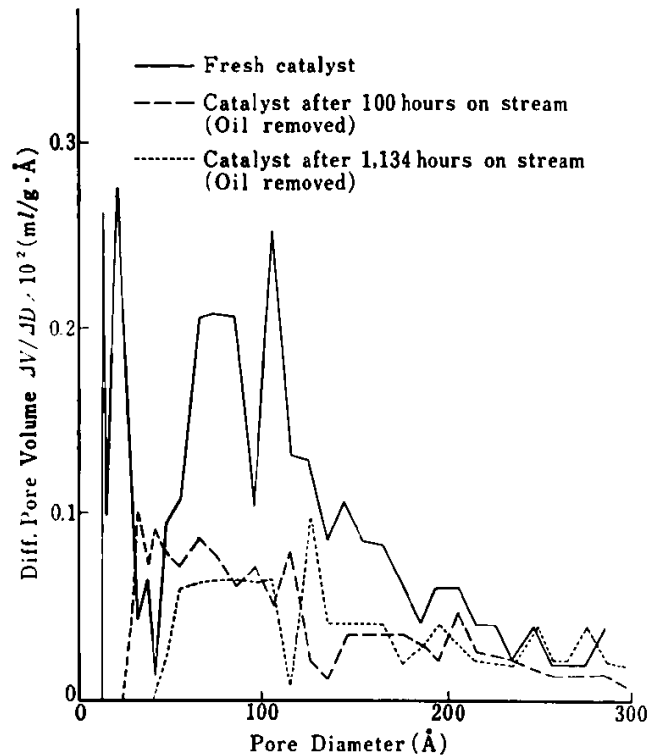

Fig. 1 Pore Size Distribution of KS-41

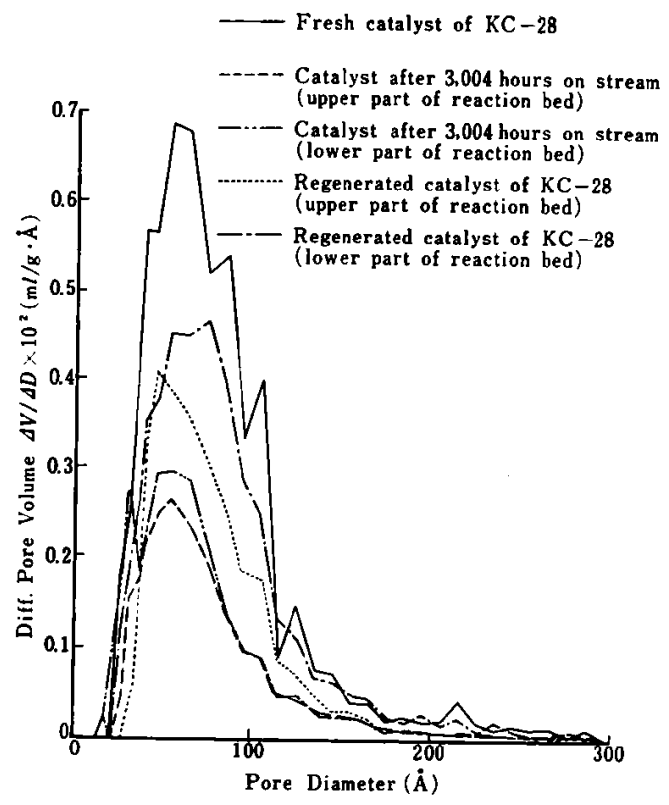

Fig. 2 Pore Size Distribution of $\mathrm{KC}-28$

sited on the catalyst. As for the disappearance of pores in the period from 100 hours to 1,134 hours on stream, the influence of the plugging up of pores by metals deposited on the catalyst was considered.

Next, pore size distributions of the catalyst used from 2,000 to 3,000 hours were studied with the following three kinds of samples, that is, fresh catalyst, regenerated catalyst and the used catalyst subjected to the oil removal treatment and the results obtained are shown in Fig. 2, 3, 4 and 5. As is seen in Fig. 2, the peaks of the pore size distribution curves of the used

Volume 14, No. 2, November 1972

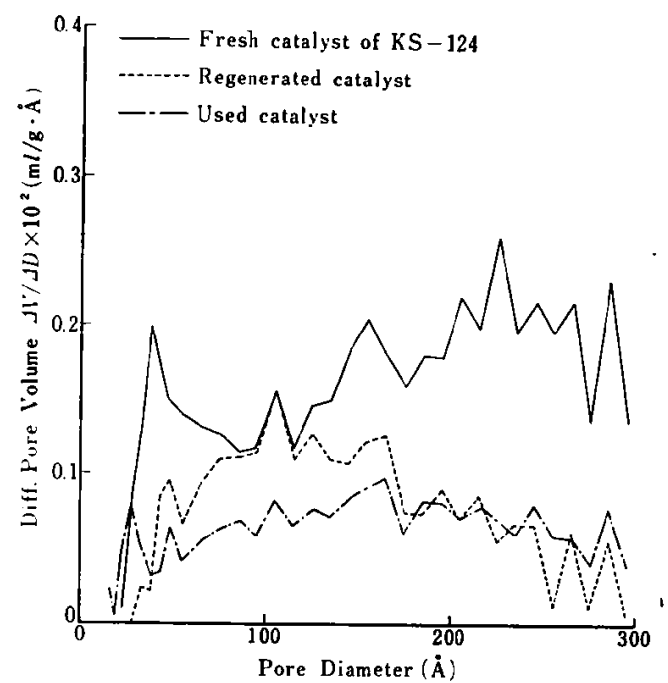

Fig. 3 Pore Size Distribution of KS-124

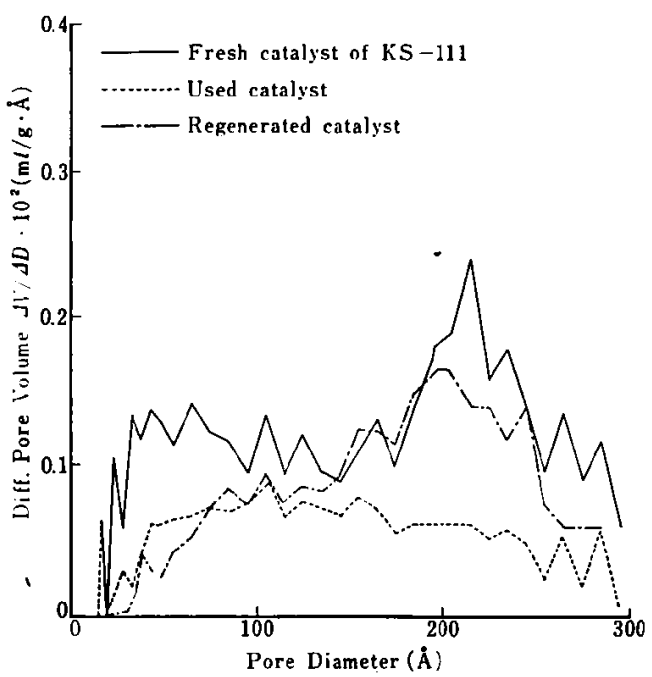

Fig. 4 Pore Size Distribution of KS-111

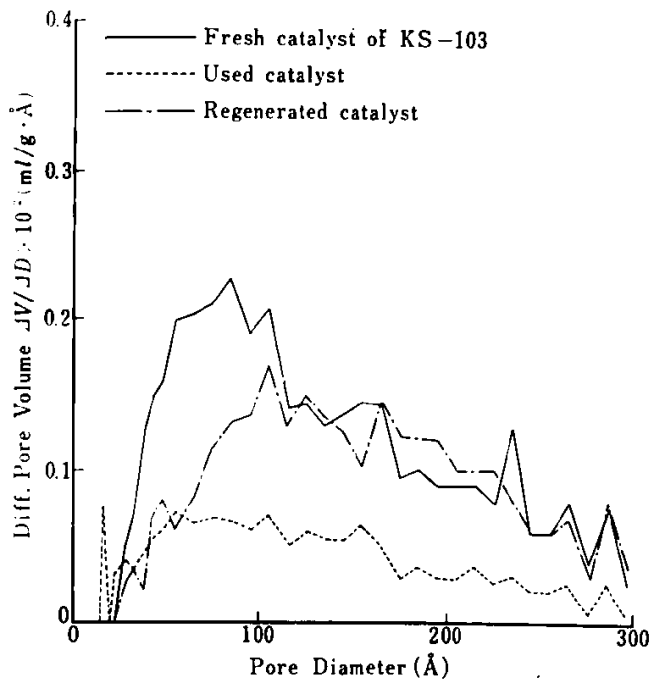

Fig. 5 Pore Size Distribution of KS-103 
catalyst $\mathrm{KC}-28$ before regeneration, the mean pore diameter of which was small, tended to shift toward the smaller pores for both the upper and the lower part of the catalyst bed. On the other hand, the peaks of the regenerated catalyst tended to shift toward the larger pores than those of the used catalyst. Moreover, the decrease in the pore volume of the used catalyst in the upper part, was more remarkable, while the recovery of pore volume after regeneration was remarkably small in the upper part.

Now, as can be seen from the pore size distribution curves, the difference in the pore volumes between the fresh catalyst and the regenerated catalyst suggested that the metals deposited inside the pores, and the difference in the pore volumes between the used catalyst and the regenerated catalyst suggested that deposition of carbon occurred inside the pores. From the above considerations, the metals seemed to deposit inside the pores and plugged up beginning from the smaller to the large pores; on the other hands, carbon seemed to deposit in the relatively large pores within a short period of time. This well agreed with the results obtained by $\mathrm{X}$-ray microanalyzer ${ }^{3}$.

As is seen in Fig. 3, the pore size distribution curves of KS-124 were different from those of $\mathrm{KC}-28$. In KS-124, the mean pore diameter was comparatively great and the pore size distribution was broad; and the effect of plugging up the pores by metal deposit was observed among the pores from 100 to $300 \AA$ in diameter and also the amount of the metal deposit seemed great. These results well agreed with the facts studied in the long run tests that the larger the mean pore diameter a catalyst was, the more the amount of metal deposited ${ }^{2)}$. The most remarkable effect of plugging up of pores by carbon deposit was seen in the range of pores from 60 to $160 \AA$ in diameter. The similar tendency was seen in KS-111 and KS-104 as shown in Fig. 4 and 5.

In the following, $\mathrm{KC}-28, \mathrm{KS}-124$ and $\mathrm{KS}-103$ were compared. In case of KS-103, the pore size distribution of pores above $100 \AA$ was regenerated to a state of similar distribution of the fresh catalyst. From Fig. 5, it was supposed also that, the effect of plugging up of pores by metal deposit was small. This may reasonably be estimated from the fact that reaction temperature of $\mathrm{KS}-103$ was limited to $410^{\circ} \mathrm{C}, 20^{\circ} \mathrm{C}$ lower than that of other catalysts; accordingly, the metal removal reaction which took place in parallel with sulfur removal reaction was suppressed.

\subsection{Activity of Regenerated Catalysts}

As is seen in the pore size distribution of regenerated catalyst $\mathrm{KC}-28$, the difference in the degree of recovery of pores by regeneration was found between the upper part of the catalyst bed and the lower part. In order to investigate the effect of this difference on the catalytic desulfurization activity, the catalysts used for the long run activity tests were divided into two parts, the upper and the lower part, and the activity of each part was tested under the same reaction conditions described previously. The results are shown in Fig. 6.

As is seen in Fig. 6, the catalyst of the upper part, after 100 hours on stream, showed a sulfur removal of $48 \%$; on the other hand, the catalyst in the lower part showed a sulfur removal of $53 \%$. From the results regarding the deposited materials on the surfaces of the catalysts described in the previous work, the difference in sulfur removal was considered to be due to the difference in the amounts of metal deposits. For example, the amount of deposited vanadium was $5.5 \mathrm{wt} \%$ for the upper part and $4.5 \mathrm{wt} \%$ for the lower part.

The catalyst used for desulfurization of distillates for more than 6 months and on which 8.4 $\mathrm{wt} \%$ of carbon was deposited was regenerated and subjected to the hydrodesulfurization test of the Kuwait residual fuel under the same reaction

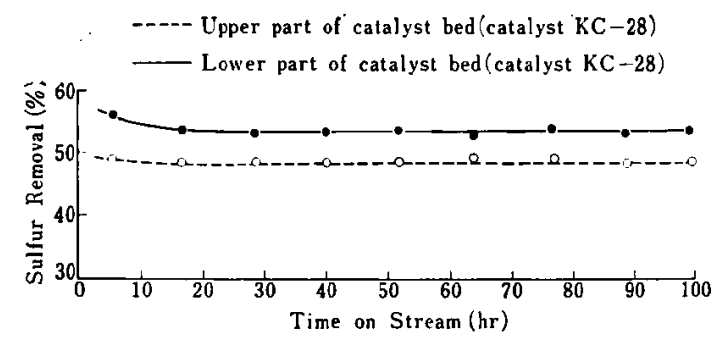

Fig. 6 Desulfurization Activity of Used Catalyst in Long Run Activity Tests

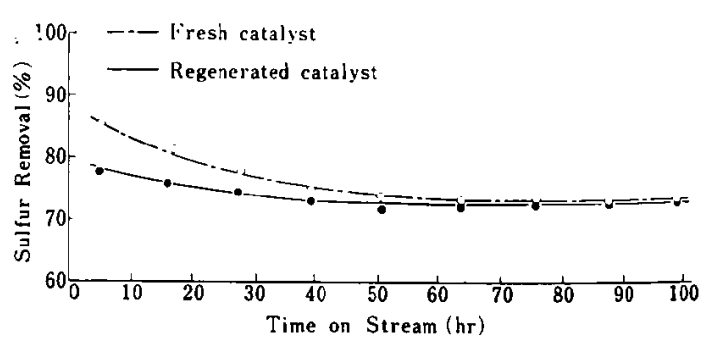

Fig. 7 Desulfurization Activity of Regenerated Catalyst

Bulletin of The Japan Petroleum Institute 
conditions as mentioned previously, and its hydrodesulfurization activity was compared with that of the fresh catalyst. The results are shown in Fig. 7. As is seen in Fig. 7, sulfur removal after 100 hours on stream was about $74 \%$ for both catalysts and the decrease in activity of the regenerated catalyst was not observed. Therefore, when the decrease in activity was due to the carbon deposit on the catalyst, its activity was considered to be recoverable completely by regeneration. The difference in the physical properties between the regenerated and the fresh catalyst was found to be very slight.

The activity of catalyst $\mathrm{KC}-28$ was tested under the following conditions: the fresh catalyst under the same reaction conditions as mentioned previously; the used catalyst for 2,120 hours under the same reaction conditions as those of 100 hours on stream from the time the reaction temperature had been raised to $410^{\circ} \mathrm{C}$, and the regenerated catalyst used for 3,000 hours under the same reaction conditions. The results obtained are shown in Fig. 8. As is seen in Fig. 8, the sulfur removal of the fresh catalyst was about $71 \%$ for both after 50 hours and 100 hours on stream, that after 2,170 hours and 2,220 hours on stream showed $63 \%$ and that of the regenerated catalyst after 50 hours and 100 hours on stream was about

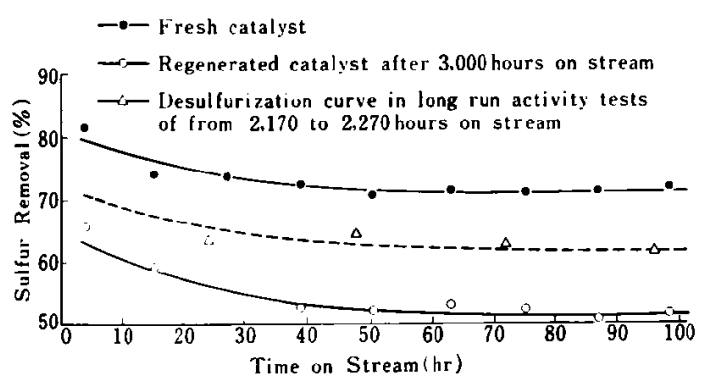

Fig. 8 Desulfurization Activity of Regenerated Catalyst

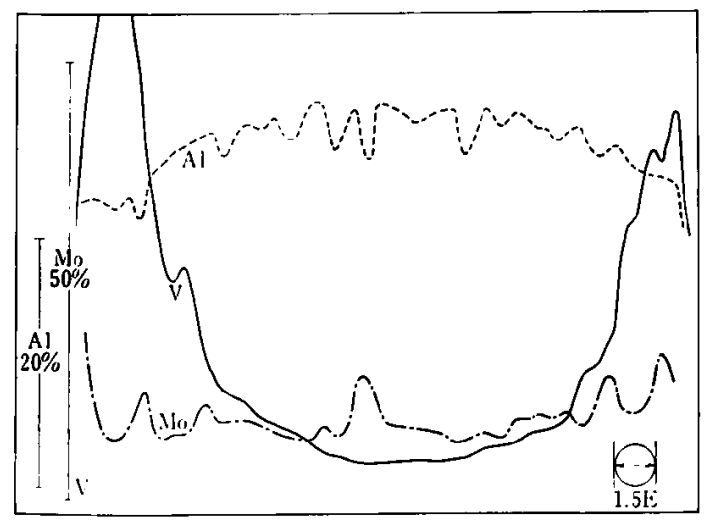

Fig. 9 Deposited Vanadium on Catalyst Surface
$51 \%$. The sulfur removal of the regenerated catalyst was $20 \%$ lower than that of the fresh catalyst and it was observed to be very similar to that shown in Fig. 6. As for the above results, it could be reasonably estimated that regeneration, which was very effective for removing the carbonaceous deposits on the catalyst, was unable to remove the metal deposits to recover the activity of the catalyst.

The state of the deposited vanadium obtained by $\mathrm{X}$-ray microanalyzer is shown in Fig. 9. By analyzing the results, $\mathrm{V}_{2} \mathrm{O}_{5}$ of reddish orange color was observed to exist on the coaxial circle of the catalyst which corresponded to the peaks of the deposited vanadium. From the fact that the melting point of $\mathrm{V}_{2} \mathrm{O}_{5}$ was $690^{\circ} \mathrm{C}$, the vanadium which existed in the form of a sulfate on the catalyst, was considered as transformed to $\mathrm{V}_{2} \mathrm{O}_{5}$ by regeneration and furthermore, to glassy material by hot spots during regeneration; thus vanadium deposited in the form of glassy material plugged up effectively the pores, which were the catalyst activity sites, and as a result, it decreased the catalyst activity.

\section{Conclusions}

1) The catalysts used for the long run activity tests suffered losses of their specific surface areas amounting to $40 \%$ of the original values of the fresh catalysts. The specific surface area after regeneration recovered to $50 \%$ in the upper part of the catalyst bed and about $70 \%$ in the lower part. The specific surface area of catalysts after about 100 hours on stream was almost completely regenerated. The pore volume also varied in proportion to the degree of recovery of the specific surface area. The mean pore diameter became greater than that of the fresh catalyst by regeneration.

2) Pore size distribution varied remarkably during the 100 hours on stream from the start, and after that, it maintained almost the same distribution. Pores were plugged up by the deposited carbon and metals on the surface of the catalyst. The sites of plugged up pores were considered to be different for different catalysts. Pore size distribution after regeneration recovered more in the upper part of the catalyst bed than in the lower part.

3) When the decrease in the catalyst activity was caused by carbon deposition, most of the activity was recovered after regeneration.

Volume 14, No. 2, November 1972 
However, in such case in which the decrease was due to the deposited metals like vanadium, etc., since they could not be removed by regeneration, the activity was not recovered.

\section{Acknowledgement}

We express our cordial thanks to Dr. T. Shiba, Honorary Professor of Tokyo Institute of Technology for his guidance in our study; to Dr. M. Mitarai, Central Laboratory of Sumitomo Mining Co., for his cooperation in manufac- turing the trial catalysts and to Mr. Ogata of Agency of Industrial Science \& Technology, M.I.T.I. for his cooperation extended to us throughout our study.

\section{References}

1) Inoguchi, M., Nishiyama, R. et al., Bull. Japan Petrol. Inst., 13, (1), 3 (1971).

2) Inoguchi, M., Inaba, K. et al., ibid., 13, (1), 11 (1971).

3) Inoguchi, M., Kagaya, H. et al., ibid., 13, (2), 153 (1971). 